\title{
The Big Question in Creativity Research: The Transcendental Source of Creativity
}

\author{
Anatoliy V. Kharkhurin \\ American University of Sharjah, UAE \\ E-mail address: akharkhurin@aus.edu
}

\section{ARTICLE INFO}

\section{Keywords:}

Transcendence

Transpersonality

Transhumanity

\section{Article history:}

Received 24 October 2014

Received in revised form 20 December 2014

Accepted 21 December 2014

ISSN: 2354-0036

DOI: 10.1515/ctra-2015-0014

\section{A B STRACT}

In this commentary, I raise an etiological question, which has been virtually excluded from the horizon of contemporary scholarship. In spite of a long history of philosophical, mystical, and religious approaches considering the transcendent and/or spiritual sources of human creativity, mainstream creativity researchers have become gradually reluctant to acknowledge the supernatural influences in this human endeavour. This account is either disregarded altogether or re-interpreted in a way that substitutes supernatural connections with observable and measurable processes. On the one hand, the latter approach appears to fall within the premises of modern science and thereby earns substantial attention the scientific community. On the other, this could be one of the reasons why creativity research has reached its epistemological cul-de-sac. I argue that by retaining the source of creativity within an individual, one annihilates the whole constellation of personality traits and processes, which have transcendent characteristics. It is important to integrate the study of transcendent experience into the study of cognitive, personality, and environmental underpinnings of creative faculties. A possible direction for this change is offered by transpersonal psychology, which makes an attempt to resurrect an investigation of spiritual reality and integrate it in the study of modern psychology. At the end of the commentary, I sketch a transcendental model of creativity developed along the lines of a transpersonal paradigm.

I would like to start by congratulating the creativity research community on the launching of a new journal in the field. Creativity research seems to have reached its epistemological cul-de-sac. More than ten years ago, Kaufmann (2003) drew the rather bitter conclusion that "the field of creativity research was declared somewhat of a scientific disaster area" (p. 235), and since then things appear to have taken a turn for the worse (Runco, 2014). It is time to recover from disaster, and I wish to believe that this new journal assumes responsibility for a major change. The promise of a paradigm change follows from 
an introductory article (Glăveanu, 2014) revealing the major drawbacks and indicating the direction for potential modifications to creativity research. Similar to Pollock's drip painting, Glăveanu has dripped the ideas crucial to the field, in order to create a large composition.

A large composition is what seems to be missing in creativity research. In Glăveanu's (2014) words, contemporary creativity researchers do not ask 'the big questions.' In this comment, I make an attempt to raise one of these questions, which is concerned with the origins of creativity. Traditionally, the discourse in creativity investigation evolved around characteristics of a product, methods of assessment, underlying processes, personality traits, and environmental factors (Runco, 2014). There is no doubt that all these creativity attributes are important for understanding of this phenomenon. However, they represent those shards that cannot be agglutinated in one unified construct. As a result, in Kaufmann's (2003) own words, we see "the considerable fragmentation that characterizes the field of creativity, both on the level of theory, measurement and empirical research, as well as the difficulty in pointing to core ideas and research findings" (p. 235). This is what Glăveanu (2014) also pointed out in his article.

I believe that to compile a complete system of knowledge, sooner or later, one would need to face an etiological question. This question has been virtually excluded from the horizon of contemporary scholarship. The evolutionary perspective explains the origins of creativity in terms of evolutionary shaped processes of blind generation and selective retention (e.g., Campbell, 1960). A somewhat tangential systems theory assumes creativity as an emergent property resulting from a complex system of interacting and interrelated factors (e.g., Gruber, 1988). Another approach considers creativity as an urge induced either by combat with oblivion (Rank, 1932/1989), symbolic immortality (May, 1975/1994), or terror of death (Yalom, 1980).

All these approaches however, consider human cognition as a closed system (see Frankl, 1966, for criticism) and look for the source of creativity within this system (i.e., within the individual; cf. individual creativity, Niu \& Sternberg, 2006). However, it is entirely possible that the source of creativity lies beyond human cognition (e.g., divinely inspired creativity; Niu \& Sternberg, 2006). If this is the case, construction of a system of knowledge assuming its source within the system while the source lies outside this system, condemns creativity research to failure.

It is paradoxical, but there is a long history of philosophical, mystical, and religious approaches, which take a perspective considering the transcendent and/or spiritual sources of human creativity (see Runco \& Albert, 2010). Moreover, a large majority of artists ascribe their creative capacity to inspiration, which supposedly finds its origin in supernatu- 
ral sources (Garberich, 2008). Eminent creative people report inspiration from a source, which appears beyond normative human capacities. At the same time, the scientific community reveals a systematic neglect of transcendent influences on creative capacities.

This reflects a more general tendency in scientific investigation to detach the mundane from the spiritual. In his account of the separation between science and religion, Maslow (1964) argued that in an attempt to become independent, encouraged by Darwinian discovery, scientists systematically liberated themselves from everything for which religion took ownership. Spiritual values were traditionally considered as the prerogative of religion. Thus, science left spirituality to religion and took the opposite direction. It focused on methods and techniques for the acquisition of data and factual knowledge, thereby confining itself within the framework of observable reality. The focus on measurable and observable phenomena constitutes the principle of objectivity inherent to the scientific method, which appears to ignore any aspect of the human psyche, which cannot be quantified and measured. At the same time, etymologically psychology means, "study

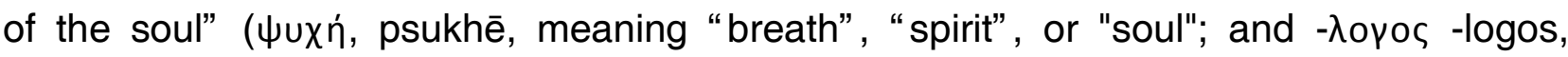
translated as "study of" or "research"). And if at the onset, using Wilber's (2000) poetic words, "psychology was still on speaking terms with the ancient wisdom of the ages" (p. $\mathrm{XI}$ ), in modern times it deals with the study of the mind and behaviour (according to the definition adopted by the American Psychological Association). Moreover, the study of the mind seems to be reduced to the study of the brain and statistical analysis of obtained patterns. A superficial review of the job market in contemporary psychology reveals that successful professionals are expected to possess extensive skills in data analysis and brain imaging techniques rather than profound insights into the 'study of the soul'.

Since an individual's spiritual experience falls beyond the technological and instrumental capacities of modern science, it has become deliberately excluded from the horizon of contemporary scholarship. Religion on the other hand devalues spirituality into the religious propagation of cult. Lacking methods for the systematic acquisition of knowledge, religion has become dogmatic and therefore cannot provide a systematic account of spiritual experience. As a result, science has lost touch with the spiritual component of phenomenal reality, and religion has not been able to acquire it.

The transcendent, spiritual, and metaphysical aspects of the human psyche to fell into a phenomenological void. Similarly, mainstream creativity researchers have become gradually reluctant to acknowledge the supernatural influences in creativity. This account is either disregarded altogether or re-interpreted in a way that substitutes supernatural connections with observable and measurable processes (e.g., insight, cf. Wallas, 1926). Creative capacity therefore, is perceived as an emergent property of normative human 
cognition (e.g., Csíkszentmihályi, 1988; Gruber, 1988). This creative cognition perspective (Ward, 2007) supposes that an individual's creative involvement can be stipulated by known and observable fundamental cognitive principles such as the capacity of one's memory systems (e.g., working memory), memory retrieval, mapping of old knowledge onto novel situations, conceptual structures, and knowledge combination and manipulation. The methodological application of the creative cognition paradigm as discussed by Glăveanu (2014) constitutes the psychometric approach in which creativity can be investigated using the conventional tools of experimental psychology. It is assumed that if creative thinking relies on the same processes as mundane thinking, one can study the former using the same methods, which are employed in studying the latter. That is, creative thinking could be effectively studied by examining the variety of observable and quantifiable processes and functions such as problem definition and redefinition, divergent and convergent thinking, synthesis, reorganization, analysis, and evaluation (Guilford, 1950).

This approach appears to fall within the premises of modern science and thereby earned substantial attention within scientific community. At the same time, as stated earlier, creativity research has reached an epistemological dead end, possibly, due to a schism between divinely inspired and individual creativity. I believe that by retaining the source of creativity within an individual, one annihilates the whole constellation of personality traits and processes, which have transcendent characteristics. As Runco (2014) rightly pointed out, "the traditional scientific method, with objectivity as its centrepiece, does not apply perfectly to creative studies. By all means we need to be scientific about creativity, but not when extreme objectivity precludes a realistic understanding of the subject matter" (p. 37). In this regard, I strongly support Glăveanu's (2014) call for a change in the creativity research paradigm and a move from the study of the observable to the study of the phenomenological. This change can be initiated by recognizing the importance of integrating the study of transcendent experience into the study of cognitive, personality, and environmental underpinnings of creative faculties.

A possible direction for this change is offered by transpersonal psychology, which makes an attempt to resurrect the investigation of spiritual reality and integrate it in the study of modern psychology. This field of psychology is rooted in Eastern mysticism, perennial philosophy, humanistic and analytic psychology, and "is concerned with the study of humanity's highest potential, and with the recognition, understanding, and realization of unitive, spiritual, and transcendent states of consciousness" (Lajoie \& Shapiro, 1992, p. 91; see Hartelius, Caplan, \& Rardin, 2007, for other definitions). Miller and Cook-Greuter (2000) edited a collection of studies investigating the relationship be- 
tween creativity, spirituality, and transcendence. They concluded: "transpersonal theory offers a strategic platform for the integration of science, humanities, religion, and the creative process" (p. XXXI).

To sketch a possible development of the transcendental paradigm in creativity research, I propose a model of creativity that reflects four creativity attributes: novelty, utility, aesthetics, and authenticity (Kharkhurin, 2014). Each of these attributes is assumed to be reflected and fulfilled in creativity spheres: a transcendental sphere corresponds to authenticity; an intellectual sphere - to novelty; an emotive sphere - to aesthetics; and an active sphere - to utility. This model employs the analogy with Lurianic Kabbalah and proposes that the human creative act starts from the urge to re-enact the act of Creation. The transcendental sphere relates the human creative act to the divine act of Creation and represents an authentic impulse to create, a creative faculty. The realization of this faculty at the conscious level emanates three other spheres that emerge as a two stage process. First, emergence of the intellectual sphere stipulates idea conception. Second, emergence of emotive and active spheres stipulates idea realization and production. These spheres represent the epistemological and empirical aspects of creativity. They account for personality traits, cognitive functions, and environmental factors, which are necessary to realize the creative urge. The conscious layer addresses the empirical findings in contemporary creative research. The model presents these spheres like Chinese puzzle balls, one contained within the other, with the transcendental sphere at the innermost layer and the active sphere at the outermost layer. Further, the creative faculty of the transcendental sphere propagates itself throughout the other spheres in the form of three creative forces. An expansive force is characterized by the processes of expanding, revealing, and generating. A restrictive force is characterized by the processes of constraining, concealing, and shaping. An integrative force combines, merges elements into a qualitatively new entity. These forces ensure dynamic and balanced processing within each sphere. Finally, the model assumes that the creative processes in each sphere take place in parallel and that the order of occurrence is not stipulated. The spheres represent the qualitatively different processing underlying creative thinking rather than their chronological order. The spheres represent the states of the creative mind rather than stages of creative thinking. This model will be detailed in future research. 


\section{REFERENCES}

Campbell, D. T. (1960). Blind variation and selective retentions in creative thought as in other knowledge processes. Psychological Review, 67, 380-400.

Csíkszentmihályi, M. (1988). Society, culture, and person: A systems view of creativity. In R. J. Sternberg (Ed.), The nature of creativity: Contemporary psychological perspectives. (pp. 325-339). New York, NY: Cambridge University Press.

Frankl, V. (1966). Self-transcendence as a human phenomenon. Journal of Humanistic Psychology, 6, 97-106.

Garberich, M. D. (2008). The nature of inspiration in artistic creativity. (3348106 Ph.D.), Michigan State University, Ann Arbor. ProQuest Dissertations \& Theses A\&I database.

Glăveanu, V. P. (2014). The Psychology of Creativity: A Critical Reading. Creativity. Theories - Research - Applications, 1, 10-32; DOI: 10.15290/ctra.2014.01.01.02

Gruber, H. E. (1988). The evolving systems approach to creative work. Creativity Research Journal, 1, 27-51.

Guilford, J. P. (1950). Creativity. American Psychologist, 5, 444-454.

Hartelius, G., Caplan, M., \& Rardin, M. A. (2007). Transpersonal Psychology: Defining the Past, Divining the Future. Humanistic Psychologist, 35, 135-160, DOI: $10.1080 / 08873260701274017$.

Kaufmann, G. (2003). What to measure? A new look at the concept of creativity. Scandinavian Journal of Educational Research, 47, 235-251.

Kharkhurin, A. V. (2014). Creativity.4in1: Four-criterion construct of creativity. Creativity Research Journal, 26, 338-352; DOI: 10.1080/10400419.2014.929424.

Lajoie, D. H., \& Shapiro, S. I. (1992). Definitions of transpersonal psychology: The first twenty-three years. The Journal of Transpersonal Psychology, 24, 79-98.

Maslow, A. H. (1964). Religions, Values and Peak-experiences. Columbus, OH: Ohio State University Press.

May, R. (1975/1994). The courage to create. New York: Norton.

Miller, M. E., \& Cook-Greuter, S. R. (Eds.). (2000). Creativity, spirituality, and transcendence: paths to integrity and wisdom in the mature self. Stamford, CN: Ablex Publishing Corporation.

Niu, W., \& Sternberg, R. J. (2006). The philosophical roots of Western and Eastern conceptions of creativity. Journal of Theoretical and Philosophical Psychology, 26, 18-38.

Rank, O. (1932/1989). Art and artist: creative urge and personality development (C. F. Atkinson, Trans.). New York, NY: Norton. 
Runco, M. A. (2014). Creativity: Theories and themes: Research, development, and practice (2 ed.). Boston, MA: Elsevier Academic Press.

Runco, M. A., \& Albert, R. S. (2010). Creativity research: A historical view. In J. C. Kaufman \& R. J. Sternberg (Eds.), The Cambridge handbook of creativity (pp. 3-19). New York, NY: Cambridge University Press.

Wallas, G. (1926). The art of thought. London: J. Cape.

Ward, T. B. (2007). Creative cognition as a window on creativity. Methods, 42, 28-37.

Wilber, K. (2000). Integral psychology : consciousness, spirit, psychology, therapy. Boston, MA: Shambhala.

Yalom, I. D. (1980). Existential psychotherapy. New York, NY, US: Basic Books.

Corresponding author at: Anatoliy V. Kharkhurin, Department of International Studies, American University of Sharjah, P. O. Box 26666, Sharjah, UAE

E-mail: akharkhurin@aus.edu 